\section{Yellow Pages: \\ It is All About File Management}

Joy Don Baker, PhD, RN-BC, CNE, CNOR, NEA-BC
This manuscript version

is a rendition of

the author's post review copy.

The official version of record

is available at the

Perioperative Nursing Clinics site.

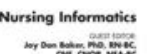

PERIOPERATIVE

NURSING

CLINICS

\title{
KEYWORDS
}

- File management $\bullet$ Personal information management $\bullet$ Structure

- Organization

\section{KEY POINTS}

- Organizing categories of Personal Information Management system.

- Role of memory relative to file management.

- Purposes for using a Personal Information Management system.

- Example assignment related to collection, storing, and distribution of evaluated Web sites.

File management is one subset of the broader term Personal Information Management (PIM). PIM subsets incorporate Web site bookmarking and e-mail management, ${ }^{1}$ "managing appointments, to-do lists, and contact management." ${ }^{2(\mathrm{p} 42)}$ There are five organizing categories of PIM: "hierarchical, flat, linear, spatial, and network." ${ }^{\prime(p 1)}$ PIM is the system used to store electronic and tangible (hard copy) materials such as documents, spreadsheets, photos, e-mail messages, books, and magazines ${ }^{1,3}$ gathered over time by a perioperative registered nurse (RN).

This article explores organizing categories as a framework for PIM. A brief exploration of the role of memory in PIM and rationale for using a predefined method for storage and retrieval of data are provided. Purposes for using a PIM system identified in this article are related to quality improvement, staff development, and patient and academic education. One application example activity/assignment illustrates the use of file management to gather, store, and distribute evaluated Web sites. Barriers that must be overcome and benefits to PIM are also discussed. Specific implications regarding perioperative nurses and nursing relative to PIM are suggested throughout the article.

The author has nothing to disclose.

College of Nursing, University of Texas at Arlington, Box 19407, 411 South Nedderman Drive, Arlington, TX 76019-0407, USA

E-mail address: jdbaker@uta.edu

Perioperative Nursing Clinics 7 (2012) 223-235

doi:10.1016/j.cpen.2012.02.006@ 2012 Elsevier Inc. All rights reserved. 


\section{GROUP INFORMATION MANAGEMENT}

Shared materials or social context ${ }^{1}$ fall into a separate arena called Group Information Management, ${ }^{4}$ and the devices used to access the information are becoming more prevalent as well, such as using an iPhone and pushing the same information into an iPad and desktop computer using a cloud system to share data with others. Combining information without being overwhelmed or resulting in a reduction of productivity is a priority key element of future planning by designers and system developers. ${ }^{1}$

\section{PURPOSES OF PIM}

\section{Quality Improvement}

The system for reviewing an environmental, health, and safety management system is the foundational base connecting all elements of the electronic health record (EHR) activities and processes. ${ }^{5}$ A generic management system was identified and necessary to create a series of voluntary environmental standards. Standards such as those used in ISO 14000 provide a model suggesting processes to reduce harmful environmental effects. ${ }^{6}$ The use of the Perioperative Nursing Data Set (PNDS) is a perioperative model and provides the language coded for data collection that can be used for quality improvement.

\section{Staff Development}

Tracking of personnel attendance at education sessions for in-service or continuing education is one purpose of PIM. It is also important to determine if education is making a difference in the outcomes of the patients, for example, safety initiatives in the perioperative setting such as hypothermia upon admission to the post anesthesia care unit (PACU). The tracking of incidences and related education initiatives may or may not correlate directly, however, without the data one cannot know. Data can provide answers to whether attending an educational session on culture diversity also exploring age-related care makes a difference in outcomes for patients. The RN's receptiveness to information and whether it is new, reinforcement, or so far out of his or her reference field that it holds absolutely no value for him or her must be considered. Cognitive learning must be evaluated as well as the effectiveness of the distribution method. Distribution methods vary from interactive processes to more of the sage-on-stage format where there is neither real responsibility nor accountability for self-learning.

Basing the information collection relative to staff development on the PNDS data elements can assist in determining additional learning needs for the perioperative setting staff. For example, identifying the effects of a just culture and the changes necessary to cause that to occur while at the same time determining milestones to monitor to maintain the just culture are also critical elements for exploration. Generally, if it is not important to the leaders of the system, it will not be a priority for the RN in the system either.

\section{Patient Education}

Patient education is similar in nature, as we must be able to articulate the specific outcomes that we wish to achieve and relate those to the PNDS for monitoring the results and feedback from patients. Consider, for example, a patient who is diagnosed with a critical disease in which death will occur without a surgical procedure. The procedure will require significant blood replacement and the patient's religion forbids blood and blood product use. Exploration of data indicating best practices 
and resources that can be tapped into to assist with this patient are essential. Knowing where these resources are located and who has the rights to access them are two elements for exploration. The ethical principles at work in this scenario are also important to explore as well the frequency of occurrence in the setting. Determining the PIM for patient education and the outcomes related also needs to be connected to the PNDS, as that is a ready tool for coding data for future analysis.

\section{Academic Education}

Teaching individuals how to learn and manage their own personal information can be a challenging endeavor. Given that, individuals may have the filer or the piler type of PIM strategies already at work. One of the outcomes for the Masters N5308 Nursing Informatics course that I teach is to apply personal skills in use of information technology appropriate to nursing practice, education, and research. One of the assignments in the course is what we refer to as the Yellow Pages assignment (J.D. Baker, Hough $\mathrm{H}$, Yellow Pages assignment for N5308 Nursing Informatics, Unpublished document, University of Texas at Arlington, College of Nursing, Arlington, TX, 2011). In this assignment, Web pages are utilized as the only files, with the exception of the folder summary documents and the Table of Contents document. The process that is taught can apply to other file formats, but to narrow the volume we selected only Web sites. The file management technique is a hierarchical process with forced main topics in which files may be used only once in any part of the compact disc (CD) created by the student (see Appendices A and B).

Students have indicated that after completing the assignment they plan to clean up their files on their computer or multiple flash drives so they can locate items more readily. They also have indicated the value of this relative to management of their e-mail as well instead of having everything in the Inbox and Sent box. Students have indicated there is value for creating CDs for patient education. CDs are a low-cost means of conveying information to patients. The patients can be assured of the quality of the Web pages or documents housed on the CD because the items have been preevaluated by the RN. Perioperative nurses can use this same process for dissemination of content, relevant sources, instructional materials, and so forth to patients or staff.

\section{ORGANIZING CATEGORIES} Hierarchical System

The hierarchical system is the more common method of PIM, allowing for a logical as well as an intuitive approach. Operating systems such as Windows utilize a hierarchical system to manage and organize files. 1 This hierarchical system uses a series of folders, subfolders, and file names to facilitate the management of the information. This is similar to that of a library subject category system for locating similar references and was a consistent strategy used by participants in a mechanical engineer's study. ${ }^{7}$ An example of the hierarchical system in the perioperative setting could be the implementation of a new piece of equipment requiring education, practice sessions, servicing and cleaning processes, budget, etc. that are the primary or main folder labels. Subsets or subfolders of education might be users (RNs, Surgeons, Central Service Technicians, Biomedical staff, etc), training materials, and scheduling (equipment, rooms, sequence, etc). Individual items retained under each of the main or subfolders could be either electronic files or hard copy files such as participant handouts. This hierarchical system, although cognitively oriented, can also be difficult to maintain as the files and project components expand over time. 


\section{Flat}

The flat system is a method of "assigning tags or attributes to information items."1(p4) This is done in social networking systems in which a photograph is posted so friends may view it and the individuals within the photograph are highlighted with their associated name(s) identified, thereby tagging the image. Attributes assigned to the same photograph could be the event title, location, date, time, etc. Multiple tags may be assigned to a document or file allowing any of the identified tags or keywords to be used to search for an item. ${ }^{1}$ Web-based examples of this can be found in these sites "sharing photos (http://www.flickr.com), Web bookmarks (http://del.icio.us), and articles (http://www.citeulike.org)."1(p4) An example of the flat system in the perioperative setting might be using the previous scenario of implementing a new piece of equipment; therefore, associated tags might include handouts, equipment name, vendor, etc. This process does take time to annotate the items effectively and consistently.

\section{Linear}

Linear structures allow for searching based on a particular attribute for comparison with other items in the system. Examples are "the order of words in dictionaries (alphabetical), entries in weblogs (chronological), and incoming email inboxes (chronological)." ${ }^{1(\mathrm{p} 6)}$ The downside to this type of structure is it can lose dimension such as alphabetic dimension of the item while holding another such as chronological order or the reverse. ${ }^{1}$ A perioperative example would be maintaining the minutes of the educational sessions for the new equipment listed in chronological order. One has to remember which meeting a particular issue was addressed to be able to locate it in the future. The ability to find the information by product or vendor name could be lost.

\section{Spatial}

The computer desktop as a file location is an example of spatial structure. The spatial feature relies on the premise that what is important is on top and allows for quick access. ${ }^{1}$ Limitations of this type of PIM system are size of computer monitor, and resulting significant cluttering of the desktop can occur. The spatial memory method can result in poor performance as an information retrieval process. ${ }^{1}$ This process can work for perioperative nursing, for example, using the same scenario of the equipment implementation project if on the desktop one main folder is maintained in the spatial method of the computer desktop. A hierarchical system is used for the subset folders. The project is retained on the desktop because of its priority nature, but other methods can be employed to streamline the management of the desktop to avoid clutter. Once the project is completed, the folder on the desktop housing the entire project materials may be either deleted or archived into another storage system location.

\section{Network}

The World Wide Web (WWW) is an example of a global network structure. The network type of system allows connections to be made among information elements in an arbitrary fashion. ${ }^{1}$ This system has less structure and is easy for the user to get lost. ${ }^{1}$ Connections among information elements are made with a Uniform Resource Locator (URL); information then can be connected in a database using the same identifier. One example of this is using bibliographic software such as Endnotes or RefWorks, which can be used to track references such as books and journal 
articles using a link to a location hosting the actual document. ${ }^{8}$ Another example is using the PNDS codes containing formal definitions. If these are converted to a URL as a tag this then allows a search of the various items/data based on that URL within the WWW or database, allowing information to be retrieved for exploration and analysis.

\section{PERSONAL STYLE DEVELOPMENT}

Every person and hospital system will have a preferred PIM category style. ${ }^{1}$ Variations might range from an individual who prefers a hierarchical system and regularly updates his or her folders, adding, deleting, and editing files. However, others may prefer all information items to reside in a central location such as My Documents on the Desktop. ${ }^{1}$ Others may need a chronological process to manage, for example, a sequence within a project. ${ }^{1}$ If one is interested in sharing Web bookmarks, then tagging may be the system of choice. ${ }^{1}$ No matter the preference choice, there is occasionally a need for restructuring as needs change. To date there is still a need to allow integration of categories of PIM without duplication, creating more layers for data mining purposes that can be specific and relevant to the items searched.

Having access to multiple means of retrieving information particularly may help users as the methods become more integrated in the future. Depending on the system, users must remember document filenames, the date in which it was created, or the tag with which it was associated. ${ }^{1}$ In the future, if an individual can remember one PIM system such as file or folder name, date, tag, etc. when searching it may be enough to locate an item. For now, each person selects a PIM method based on individual choice that will work best under the particular circumstances experienced and preferences for record management. For example, if one person is very organized with a clean desk then a hierarchical system might be an option and might be labeled as a filer. If the individual is more of a piler (a type of short-term memory) then a spatial organization on the desktop may be his or her choice. ${ }^{9-11}$ Spring cleaners function under the rule of thumb that out of sight is out of mind. The spring cleaner may either delete old files or add to folders; however, the item(s) are no longer visible, which can reduce the stress of seeing large open files or piles of materials.

\section{ROLE OF MEMORY IN PIM}

Three different types of memory play a role in the PIM. ${ }^{9}$ The first is semantic memory; for example, when retrieving the item or object from the personal databases it is in a textual format such as consistent folder or file name variation theme. The second is autobiographical memory and suggests one has had a previous experience with the item. The third is that of temporal reference or memory indicating that it was recently accessed, for example, last week. ${ }^{9}$ Memory problems develop relative to retrospective issues such as forgetting details, past event, or information acquired in the past. ${ }^{9}$ A second memory problem is prospective or failure to remember a future task, commitment, appointment, etc. ${ }^{9}$ The final memory issue is action slips that are "short term memory failures, which cause problems for actions currently being carried out, e.g., forgetting why one went upstairs, or losing one's train of thought, etc." ${ }^{9(p 927)}$

\section{PIM STRATEGIES/OUTCOMES}

Having the intended outcomes or end results in mind can help establish the rationale for one strategy over another. Taking time to think critically regarding how the PIM systems currently in use fit with the vision, mission, and philosophy of both the employer and individual is important. One's personal learning style may influence the selection of system management strategies. Cognitive learning can take place at 
various points in the process of storing items for future retrieval. The terms used to label a file today may have significant impact on use tomorrow. Color choice can be a part of this process. For example, Rainbow Folders ${ }^{12}$ is a free download that allows color coding folders to visually assist with storing decisions and retrieval.

\section{FILE TYPES: SKILLS AND ACCESS}

There are four types of management related to e-mail, content, Web pages, and interactive sites such as blogs or wikis. As technology continues to explode on the scene, accessing with the appropriate devise requirements varies as much as the diversity within the human population. There are always costs to upgrades and changes and as these adjustments become the standards, a chasm of continuing a class system gap rears its ugly head. When these changes occur, it may also cause the individual to adjust his or her method of PIM.

\section{E-mail Management}

E-mail celebrates its 40th birthday in 2011. Ray Tomilison sent the first e-mail message in 1971. ${ }^{13,14}$ E-mail has "three key functions in PIM: task management, personal archiving, and contact management." ${ }^{15(p 68)}$ The primary problem is that e-mail systems do not handle all of the functions well. Leaving the task-related item in the Inbox is one means of handling priority as long as the size of the Inbox is manageable. A large number of messages in the Inbox makes it more difficult to manage and locate specific task-related items. ${ }^{15}$ There are three management strategies: (1) folders textually distributing messages based on subject or content; (2) searching; and (3) sorting "for accessing archived information."15(p71) The final function of contact management is generally good in e-mail systems; however, it is sometimes difficult to retrieve information as it often takes a manual process to search and identify the relevant contact sought. ${ }^{15}$ The use of sender, recipient, and date also provides cues for locating messages in e-mail systems. ${ }^{15}$ The user-subjective principles ${ }^{3}$ are both similar and different on some levels. The three principles are project classification, importance, and context. ${ }^{3}$ For the project, everything relative to the project would go under this classification. For the importance, filing is based on value to the user. The final one, context, indicates that the "information should be retrieved and viewed by the user in the same context in which it was previously used, to bridge the time gap between these two events." ${ }^{3(\mathrm{p} 237)}$ Within the element of context, four attributes were identified: external, internal, temporal, and social. ${ }^{3}$

Strasser ${ }^{14}$ suggests six key elements for managing e-mail:

1. Handle messages similar to that of traditional inboxes and written communications.

2. Decide what must be done with the message.

3. Manage mailbox size.

4. Back up periodically.

5. Retain messages and attachments as you would other documentation.

6. Monitor for viruses. ${ }^{\text {(p506) }}$

If one assumes that between $75 \%$ and $80 \%$ of the e-mail messages received are classified as spam or junk, then applying the Pareto principle (Box 1) or 80/20 rule indicates that $80 \%$ of our time when reviewing e-mail is spent with distractors and unproductive time wasters. Missed or forgotten commitments ${ }^{16}$ creates another element of the $80 \%$ misuse of time. Although scheduling systems such as Microsoft 
Box 1

Pareto principle

Pareto principle: Vilfredo Pareto's (economist) rule states, "That a small number of causes is responsible for a large percentage of the effect, in a ratio of about 20:80. Expressed in a management context, $20 \%$ of a person's effort generates $80 \%$ of the person's results. The corollary to this is that $20 \%$ of one's results absorb $80 \%$ of one's resources or efforts. For the effective use of resources, the manager's challenge is to distinguish the right $20 \%$ from the trivial many."

Reprinted from Hafner AW. Pareto's principle: the 80-20 rule, 1-3. Available at: http://www.bsu.edu/libraries/ahafner/awh-th-math-pareto.html.

Outlook do help bring some of the elements together such as e-mail, appointment scheduling, and to a lesser degree task management, they do not help with the vast amount of unnecessary e-mail that one must deal with on a daily basis.

Allen ${ }^{17}$ suggests sorting the e-mail content into four categories: Trash, Tickler, Reference, and Action. ${ }^{17}$ These categories are not that dissimilar to those identified by Covey, ${ }^{18,19}$ which use a chi square $(\times 2)$ grid to aid in decision making. Covey's categories are (1) Urgent (crises, pressing problem, or deadline driven); (2) Not Urgent and important (category in which one should spend the greater portion of the time available); (3) Interruptive Activities may have some degree of urgency; however, these are most often someone else's priority; and (4) Trivial Activities, which are generally not urgent or important; they represent the time wasters procrastination deluxe opportunity. ${ }^{18}$

Barreau identified five filing systems used by her participants that are related to tasks, topic, time, provenance, and form. ${ }^{10}$ She suggests there are "three types of information in the workplace: ephemeral, working, and archived." ${ }^{10(p 307)}$ "Ephemeral information has a relatively short shelf life, but requires prominent placement in the work space so that it will not be overlooked."10(p308) Working information is content used often over a period of time. ${ }^{10}$ "Archived information has long-term value but isn't being used in the current work at hand."10(p308)

\section{Other File Types}

Content-based items are documents (.docx), portable document format (.pdf), spreadsheets (.x|sx), or presentations files (.pptx) that are stored in the PIM system utilized by the perioperative nurse. The same strategies identified earlier may be employed with these items; however, they also may be relevant in more than one location for retrieval purposes. Format-based items such as those used with Web page bookmarks or favorites tend to use a flat or tagging system such as that found in http://delicious.com $/{ }^{1}$ This also provides a connection by tagging relative to categories and sharing these sites with others. Interactive-based are also a Web page format using URLs to identify and locate. Blogs and wikis are examples of such an interactive structure. Blogs provide an opportunity to display information and then allow others to comment on the content, creating dialogue among those accessing the blog. Wikis are designed for collaborative group work where the end product can be edited by all participants having access to the wiki. Managing and tracking iterations of the wiki can present a challenge.

\section{BARRIERS}

Information fragmentation ${ }^{1}$ can occur particularly as it relates to finding a specific item stored either in diverse unconnected PIM systems or on multiple "devices such as 
desktops, laptops, cell phones, and personal digital assistants (PDAs)." ${ }^{1(\mathrm{p} 11)}$ Information overload is one component driving the need for efficient and effective PIM systems. Perhaps multitasking such as using the cell phone during a meeting, reading e-mail while driving, etc. is not a good choice. "Multitasking is a terrible coping mechanism" ${ }^{20}$ for dealing with information overload and makes people less productive. ${ }^{20}$ The second issue with information overload is that it takes a great deal of self-discipline to take control of the information overload. ${ }^{20}$ The steps involve the three " $F$ " elements: Focus, Filter, and Forget. These three Fs are similar to Allen's four elements ${ }^{17}$ and Covey's quadrants ${ }^{18}$ for working with various pieces of information or interruptions. The third issue is that for change to occur the senior level executive sets the behavior and tone for the organization and he or she has the responsibility to set a better example. The productivity level of the entire organization can be affected by information overload and no one can address the issue alone. ${ }^{20}$ Multitasking slows us down, taking "up to $30 \%$ longer with twice as many errors." 20 (p2)

Storage availability also seems to be an issue, less so today than in the past. Gemmell and colleagues suggest that over a person's lifetime, less the recordings of "videos, a terabyte [of computer space] seems adequate for lifetime, storage." $21(\mathrm{p} 90)$ They suggested " $1 \mathrm{~GB} /$ month for the duration of an 80-year life assuming only modest storage" 21 (p90) needs could be maintained. I do have a few doubts because of the continuing rapid change and the opportunity to manage massive amounts of information. For example, in the late 1980s I thought a $10 \mathrm{MB}$ computer was huge and now we have flash drives that hold 10 to $20 \mathrm{~GB}$ that can fit in a small wallet. The key to this concept is to be able to store everything no matter the file, format, or original devise location. Search and retrieval become the critical elements. In addition, cost and copyright issues ${ }^{21(\mathrm{p} 95)}$ have a tendency to surface periodically and rights to storage or retrieval become restricted. The underlying issue becomes, "when everything can be captured, easily found, and utilized, it is not clear whether this capability will always be desired and in some cases allowed."21(p95) Legal and societal issues ${ }^{21}$ "relative to privacy and security implications" ${ }^{21(p 72)}$ will continue to surface and cause rich dialogue and debate, both in and outside the courts and legislative systems.

\section{BENEFITS}

Benefits to the process of collecting everything can be evaluated against the Five Rs identified by Sellen and Whittake 22 as "recollecting, reminiscing, retrieving, reflecting and remembering intentions." ${ }^{22(p 73)}$ Recollecting is the thinking back in detail past experiences or episodic memories. ${ }^{22}$ Reminiscing is the opportunity to "relive past experiences for emotional or sentimental reasons."22(p73) Retrieving could be dependent on inferential reasoning such as keywords ${ }^{22}$ and identifying alternate properties in which an item might be located, searched, or sorted. "Reflection might include examining patterns of past experiences"22(p73) similar to what is conducted in a phenomenological study. Remembering intentions is the commitment to prospective events; it is future oriented such as "run errands, take medication, and show up for appointments." ${ }^{22(p 74)}$

\section{PERIOPERATIVE NURSING IMPLICATIONS}

Examples of two folder strategies are offered: one that may fit the practice arena and one that may fit the education arenas (Box 2). Consider four primary folders as the starting point for either concept area. For the practice area, those might be labeled Work, Professional Organization(s), Education/Training, and Personal. For the education areas, 


\begin{tabular}{|c|c|}
\hline \multicolumn{2}{|c|}{$\begin{array}{l}\text { Box } 2 \\
\text { Sample folder outlines for PIM education and practice areas }\end{array}$} \\
\hline Education & Practice \\
\hline $\begin{array}{l}\text { Teaching } \\
\text { - N5308 Informatics } \\
\text { - N5382 Health Policy }\end{array}$ & $\begin{array}{l}\text { Work/Employment } \\
\text { - Orthopedic Nursing } \\
\text { - Project: Supply Management } \\
\text { - Project: Patient Safety }\end{array}$ \\
\hline $\begin{array}{l}\text { Service/Professional } \\
\text { - AORN } \\
\text { X NLC Region V Coordinator } \\
\text { X State Coordinator for TX } \\
\text { - ANA } \\
\text { - TCORN }\end{array}$ & $\begin{array}{l}\text { Professional } \\
\text { - AORN } \\
\text { - State Council } \\
\text { - ANA }\end{array}$ \\
\hline $\begin{array}{l}\text { Scholarship } \\
\text { - Presentations } \\
\text { - Publications } \\
\text { - Posters } \\
\text { - Grants/Funding }\end{array}$ & $\begin{array}{l}\text { Education/Training } \\
\text { - Inservices } \\
\text { - CEs } \\
\text { - Annual Requirements: BCLS, etc }\end{array}$ \\
\hline $\begin{array}{l}\text { Personal } \\
\text { - Family } \\
\text { - Friends }\end{array}$ & $\begin{array}{l}\text { Personal } \\
\text { • Family }\end{array}$ \\
\hline
\end{tabular}

Note: Each of the above items represents a folder the bulleted items represent subfolders and may hold multiple subfolder levels within one folder.

while similar, there is a slight variation on theme: Teaching, Service/Professional, Scholarship, and Personal. Under each of these headings or folders, subfolders may be created to help facilitate the PIM for the individual. An example of subfolders for the education area, for example, under the Scholarship folder, might be something like: Presentations, Publications, Posters, and Grants. An example of subfolders relative to the perioperative RN might fall under the Professional Organization(s) such as Association of Perioperative Registered Nurses (AORN) Congress, Committees, Local Chapter, and American Nurses Association (ANA). There could be more subfolders within each of these headings depending on the individual's personal selection, choices, and themes for contextual hierarchy of files.

For managing the files within the folders and subfolders, decisions have to be made regarding how they will be handled, when changes will be made, and the monitoring timeframe. Whether an item be retained for archival purposes or deleted after its purpose has been served becomes the underlying question for decision making with the PIM. Perioperative RNs are generally quality organizers and detailed planners because of the work done in the perioperative setting. This skill can be translated and used in their PIM system development.

\section{SUMMARY}

Of the five PIM categorizing systems, hierarchical, flat, linear, spatial, and network, the hierarchical seems to be the most prevalent. ${ }^{1}$ The hierarchical system uses folders and subfolders for organization. This could be an alphabetical system or 
chronological process and has merit for perioperative nurses. This article addressed file management for the purposes of searching and retrieval of data for use and analysis to improve patient care outcomes and patient safety and to address staff issues for quality improvement. Having data that provides the information to support perioperative practice decisions to continue to improve care, finding quality ways to manage and maintain access to the best practice options, and managing the data will contribute to positive outcomes for patients in the perioperative settings.

\section{APPENDIX A: YELLOW PAGES STUDENT ASSIGNMENT* Goals}

The first goal of this assignment is to utilize a systematic and usable tool for evaluating Web sites. Students may use one of the two created by former students: one is qualitative and the other is quantitative in evaluation format. Students may also choose to use one they locate from the Web that resonates more with their own use or create an entirely new one for themselves. The second goal is to use the identified Web site evaluation tool to select sites for inclusion in a personal nursing Yellow Pages CD. The student burns the various individual pages onto the CD using appropriate folders for navigating the $C D$. If the student used a quantifiable evaluation tool, we ask him or her to provide the associated score of each Web site included in the $C D$. If the student selected a qualitative evaluation tool then we ask him or her to provide information about how each site fared related to the tool. The final goal is to create a CD with detailed files and links related to the predetermined criteria. This assignment assists the student in developing skills in burning a CD for use by other(s) and management of folders and files of data using both internal and external URLs.

\section{Content Elements}

Content areas that must be addressed by the student include creating (1) a Table of Contents linking to the internal pages within the CD; (2) a copy of the Web site evaluation tool employed in the CD; (3) an introduction that is an overview of the organization of the $C D$ and rationale for key themes developed in the folders (sections); and (4) four main folders: Nursing Practice, Education, Research, and Personal Growth/Other. Within the Nursing Practice folder, students are required to demonstrate their skill in creating subfolders. Each folder and subfolder created follows the same principles of quality outline formatting; in other words, there must be a minimum of two under each heading (folder) identified. Therefore, if a student selects to use two subfolders, for example, under Nursing Practice, then there must also be a minimum of two Web page files within each subfolder. The student must also include a summary of what is included in each folder/section explaining how he or she used the evaluation tool to select the specific Web sites included and how the Web sites selected will help you in your practice or relate to the personal value and use.

There are a few DO NOTs in the guidelines for this assignment.

1. Do not include materials you consider to have little value and no direct relationship to your practice.

*From Baker JD, Hough H. Yellow Pages assignment for N5308 Nursing Informatics. Unpublished document, University of Texas at Arlington, College of Nursing. Arlington, TX.) 
2. Do not duplicate Web sites for multiple folders. If a site fits more than one folder/section, please select the best fit and that is where it needs to go.

3. Do not include just a list of URL addresses; you may indicate there are ones you wish to visit in the future but all data should have been evaluated by you.

\section{Testing and Dissemination of the CD}

On an individual Yellow Page, the student must ensure that each URL address link is active in the CD and will open the associated external Web site. On the Table of Contents students will use internal links within the CD to redirect to the folders, subfolders, and individual Yellow Pages. They will use the print screen function to capture a screen shot of each Web page to record with their annotation, tool use, and the URL (see Appendix B). In addition to the creation of the Yellow Pages CD, students in this course also create and post to the class discussion board their Top Five Web sites and annotation of each. This provides the class a comprehensive bibliography of Web sites evaluated by their peers on a variety of subjects. The final part of this assignment is the presentation of the Top Three Web sites and showcasing their Yellow Pages CD, which allow the students to practice their presentation skill.

\section{Outcomes}

With this one assignment, students create a PIM for Web sites they find relevant, learn how to burn a CD for use by someone else, generate an executive summary document we call the Top Five, and deliver a presentation to enhance their skills. Their choices of sites to include will depend on the purpose and themes they have selected for the CD. Other associated benefits are that the students begin to see the relevance of managing other information in a conscious, critically thought out method.

\section{APPENDIX B: EXAMPLE YELLOW PAGE WEB SITE}

Italics below are notes/instructions about the process and are not included in the Yellow Page document. Please do not use this Web site in your Yellow Pages.

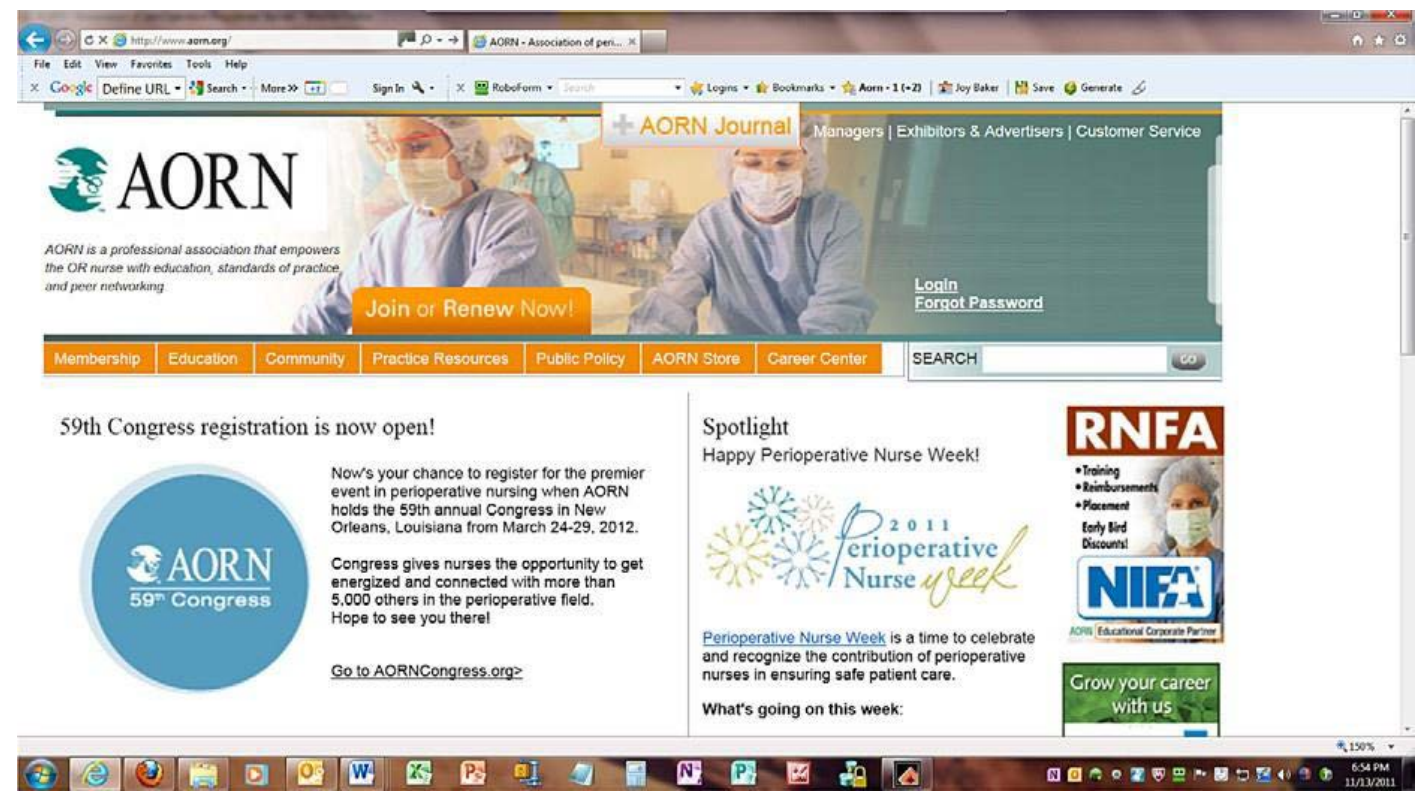


AORN: http://www.aorn.org/

Score/Analysis using Web Evaluation tool: Insert the score such as 96/100; 1 of 5 with high; or evaluation outcome from the tool you selected on each websites document. The evaluation outcome will depend on which tool was selected.

Create an Annotated note about the site:

AORN is an organization of Perioperative Registered Nurses. The site provides Educational offerings scheduling and the tab I most often frequent is Public Policy as that provides contact information and indicates the pertinent content relative to health care policy initiatives by AORN and being followed by AORN. There is a nice internal search engine that allows searching of the site for example by typing in Congress the materials for the annual convention opens. I placed the home page as the hyperlink and the print screen below instead of showing only the Public Policy webpages to provide the overview of what the site can offer.

\section{REFERENCES}

1. Vassileva I, Vassileva J. a review of organizational structures of personal information management. J Digit Inf 2008;9(1):1-19.

2. Teevan J, Jones W. Personal Information Management. Commun ACM 2006;49(1): 40-3.

3. Bergman O, Beyth-Marom R, Nachmias R. The user-subjective approach to personal information management systems design: evidence and implementations. J Am Soc Inf Sci Technol 2008;59(2):235-46.

4. Erickson T. From PIM to GIM: personal Information Management in group contexts. Commun ACM 2006;49(1):74-5.

5. Strasser PB. Management file. Environmental, health, and safety management systems and auditing programs - part II. AAOHN J 2003;51(8):327-30.

6. Strasser PB. Management file. Environmental, health, and safety management systems and auditing programs: part I-the evolution. AAOHN J 2003;51(4):161-3.

7. Hicks BJ, Dong $A$, Palmer R, et al. Organizing and managing personal electronic files: a mechanical engineer's perspective. ACM Trans Inf Syst 2008;26(4):23:21-3:40.

8. Ovadia S. Internet connection: managing citations with cost-free tools. Behav Soc Sci Libr 2011;30:107-11.

9. Elsweiler D, Ruthven I, Jones C. Towards memory supporting personal information management tools. J Am Soc Inf Sci Technol 2007;58(7):924 -6.

10. Barreau D. The persistence of behavior and form in the organization of personal information. J Am Soc Inf Sci Technol 2008;59(2):307-17.

11. Boardman R, Sasse MA. Stuff goes into the computer but doesn't come out: a cross-tool study of personal information management. Paper presented at the Proceedings of CHI, April 24-29, 2004.

12. Rainbow-Folders. Available at: http://www.freewarefiles.com/Rainbow-Folders_ program_5495.html. Accessed February 21, 2012.

13. Butler KM. Email celebrates 40th birthday: is it getting better with age? Employee Benefit News 2011;25(10):17.

14. Strasser PB. Management file. Electronic mail communication-management strategies. AAOHN J 2003;51(12):504-6.

15. Whittaker S, Bellotti V, Gwizdka J. Email in Personal Information Management. Commun ACM 2006;49(1):68-73.

16. Denning PJ. The profession of IT managing time [opinion]. Commun ACM 2011;54(3): 32-4.

17. Allen D. Getting things done: the art of stress-free productivity. New York: Penguin; 2001. 
18. Covey SR. The seven habits of highly effective people: restoring the character ethic. New York: Simon \& Schuster; 1989.

19. Covey S, Merrill A, Merrill R. First things first: to live, to love, to learn, to leave a legacy. New York: Simon \& Schuster; 1994.

20. Dean D, Webb C. Recovering from information overload. McKinsey Q 2011;(1):80-8.

21. Gemmell J, Bell G, Lueder R. My Life Bits: a personal database for everything. Commun ACM 2006;49(1):88-95.

22. Sellen A, Whittaker S. Beyond total capture: a constructive critique of Lifelogging. Commun ACM 2010;53(5):70-7. 